\title{
Understanding help seeking behaviour among male offenders: qualitative interview study
}

\author{
Amanda Howerton, research fellow', Richard Byng, primary care research network lead', John \\ Campbell, professor of general practice and primary care', David Hess, development lead', Christabel \\ Owens, honorary research fellow ${ }^{2}$, Peter Aitken, honorary clinical lecturer ${ }^{2}$
}

Primary Care Research Group, Peninsula Medical School, Exeter EX1 2LU

${ }^{2}$ Mental Health Research Group, Peninsula Medical School Correspondence to: J Campbell john.campbell@pms.ac.uk

doi: 10.1136/bmj.39059.594444.AE

\section{ABSTRACT}

Objective To explore the factors that influence help seeking for mental distress by offenders.

Design Qualitative study based on in-depth interviews with prisoners before and after release.

Setting One category B local prison in southern England. Participants 35 male offenders aged 18-52, a quarter of whom had been flagged as being at risk of self harm. Results Most respondents reported that they would not seek help from a general practitioner or other healthcare professional if experiencing mental distress. When followed up after release, none had sought medical help despite the fact that many had considerable emotional problems. Many participants were hesitant to seek help because they feared being given a formal diagnosis of mental illness. Some of these men feared the stigma that such a diagnosis would bring, whereas others feared that a diagnosis would mean having to confront the problem. Lack of trust emerged as the most prominent theme in prisoners' discourse about not seeking help from health professionals. Distrust towards the "system" and authority figures in general was linked to adverse childhood experiences. Distrust directed specifically at healthcare professionals was often expressed as specific negative beliefs: many perceived that health professionals (most often doctors) "just don't care," "just want to medicate," and treat patients "superficially." Those men who would consider going to a general practitioner reported positive previous experiences of being respected and listened to.

Conclusions Distrust is a major barrier to accessing health care among offenders. Like most people, the respondents in this study wanted to feel listened to, acknowledged, and treated as individuals by health professionals. By ensuring that a positive precedent is set, particularly for sceptical groups such as ex-prisoners, general practitioners and prison doctors may be able to encourage future help seeking. Information specifically designed for prisoners is needed to help to de-stigmatise mental illness, and preparation for release should include provision of information about access to health and social services. Awareness training for health professionals is recommended: trust might be fostered in this population by seemingly trivial gestures that indicate respect.

\section{INTRODUCTION}

Men are among those people least likely to seek help from healthcare professionals, even when experiencing severe levels of distress. ${ }^{1}$ Those who have been incarcerated have significantly higher rates of mental illness and suicide and underuse mental health services compared with the general population. ${ }^{2-5}$ Despite the psychological profile and risk factors that characterise this group-low socioeconomic status, increased levels of impulsivity and aggression, limited coping skills, social isolation, a history of self harm and attempted suicide ${ }^{6}$-no qualitative studies have focused specifically on the perceptions and beliefs that influence help seeking for this vulnerable group. Research from New Zealand suggests that a positive previous encounter with a health professional may predict the likelihood of seeking help in the future, although the nature of such encounters has not been explored. ${ }^{5}$ Although offenders' help seeking behaviour has been covered in the quantitative literature, researchers have recognised the need for qualitative work that sheds light on the underlying motives and beliefs that guide help seeking. ${ }^{7}$ In this study, our primary aim was to learn more about the factors that influence help seeking behaviour among men leaving custody, in order to inform the development of health and social care services and improve the training of professionals who may come into contact with these people.

\section{METHODS}

Interviews

We did 35 in-depth, face to face interviews with sentenced male prisoners from one category $\mathrm{B}$ local prison (second in the four categories of severity of offence) in southern England. The sample included young and middle aged participants, prisoners with short and long offence histories, and those who had currently or previously been convicted for minor or serious offences. To gain insight into the views of men experiencing mental distress, we preferentially interviewed prisoners who were flagged by the prison staff as being at risk for suicide or self harm under an assessment care in custody teamwork document. Any prisoner who attempts suicide or otherwise exhibits suicidal symptoms within the prison can be flagged under 
such a document by a member of the prison staff. Once a prisoner is flagged under this document, safeguards are put in place to prevent further incidents. Prisoners whose mental health problems are considered to be life threatening by the prison staff are transferred to the mental health wing of the prison where they are accommodated in rooms with appropriate observation facilities. We drew participants from a list of prisoners who were scheduled for release each week, sampling them until we reached the target of 35 cases, with a view to achieving data saturation within the scope of the study and sufficient follow-up interviews and in line with recent studies. ${ }^{8-10}$

A researcher (AH, a medical sociologist) approached eligible prisoners while they were in the prison and gave them a comprehensive explanation of the study. To offset potential anxiety so soon before release, she explained that their participation was voluntary and that the research was not being done by, nor was it associated with, Her Majesty's Prison Service. AH gave eligible prisoners a copy of the study description and a minimum of 24 hours to decide whether they wished to participate. Within the next few days, she returned to the prison, obtained consent, and interviewed respondents in a secure interview room in the prison. On completion of the initial interview, $\mathrm{AH}$ offered respondents a $£ 10(€ 15 ; \$ 19)$ food voucher. They invariably seemed surprised by this gesture, which indicates that it did not act as an incentive to take part.

We developed the study design and interview topic guide in partnership with "the Revolvers," the users' involvement group of the Revolving Doors Agency, a voluntary sector organisation that provides services to ex-offenders with mental health problems (www.revol vers.org.uk). We piloted the pre-release interview schedule on three members of the Revolvers based in London. It covered a variety of topics in four primary domains (box 1). However, we also encouraged participants to digress from the schedule to talk about their lives and other matters that were relevant and important to them. All topics were explored in each interview, which lasted between one and two hours.

Extant literature suggests that the first four to six weeks after release from prison are particularly hazardous with regards to risk of suicide and self harm. ${ }^{411}$ We therefore planned to follow up all participants and interview them again approximately four to six weeks

Box 1: Topic guide-domains of enquiry

Pre-release

- Family background

- Coping with stress and difficulties

- Perceived mental health and suicidal ideation

- Help seeking behaviour

Post-release

- Transition experience

- Help seeking behaviour after release. The second interview focused on the experience of transition from prison into the community, experiences of mental distress, and specific barriers to use of health services. Although our intention was to do face to face interviews at follow-up, this was not always possible in a population in which homelessness and transience are common and often compounded by other major psychosocial constraints. For these reasons, we made some follow-up contacts by letter, telephone, or text messaging.

\section{Data analysis}

We audiotaped all interviews, with permission, and transcribed them verbatim. We combined pre-release and post-release interviews and treated them as single cases. We analysed data thematically by using some of the principles of grounded theory, including the constant comparison method. We used this to identify deviant cases or exceptions to the emerging pattern of relations between codes. ${ }^{12}$ We used a variety of other techniques such as open coding of the early data, ${ }^{13}$ reflexivity methods, and peer group reviews. $\mathrm{AH}$, $\mathrm{RB}$, and $\mathrm{DH}$ met regularly to discuss the coding and interpretation of the data. We did not develop interrater reliability scores, as the interviews were relatively unstructured. ${ }^{14}$

\section{RESULTS}

\section{Characteristics of respondents}

All prisoners approached consented to be interviewed. Of the 35 interviews done before release, six were with young offenders (aged 18-20 years) (table). All but one participants were unmarried, 23 had one or more children, and $97 \%$ of the sample were white British. We did post-release interviews with 19 (54\%) of the 35 original participants. We collected basic information on participants' general circumstances and wellbeing from respondents' relatives for a further 10 participants, leaving only six with no post-release data.

As regards mental health status, a quarter of the participants had been flagged by a staff member as being at risk for suicide or self harm at some point during their time in the prison. Twenty two of the respondents reported attempted suicide at some point in their lives; six of these respondents were on an assessment care in custody teamwork document. We asked all respondents whether they had ever been formally diagnosed as having a mental health problem and whether they personally felt that they had a mental health problem (regardless of diagnosis). Several reported a formal mental health diagnosis, and many said that although not formally diagnosed they were concerned that they had a mental health problem. Many of these

Age and sentence information of prisoners $(n=35)$

\begin{tabular}{lcc} 
Characteristic & Mean & Median (range) \\
\hline Age (years) & 30 & $27(18-52)$ \\
\hline Length of sentence (months) & 6 & $4(1-30)$ \\
\hline No of previous convictions & 18 & $12(0-116)$ \\
\hline No of previous times in prison & 5 & $3(0-32)$ \\
\hline
\end{tabular}


respondents reported serious symptoms such as anxiety, hearing voices, or prolonged periods of depression. Several of the respondents who reported mental health problems commented that entering prison interrupted their drug treatment cycles.

\section{Factors that inhibit help seeking}

Of the 35 prisoners interviewed, 21 said that they would not consider consulting a general practitioner about mental health problems, seven said that they would consider doing so, and the remaining seven said that they would consider it under certain conditions. Of those who were followed up, none had had contact with either primary or secondary care for mental or physical problems during the period between release and the second interview. We identified three inter-related themes that emerged from the analysis as factors that inhibited help seeking for most of this group: chaotic upbringing, distrust, and fear of a diagnosis of mental illness.

\section{Chaotic family background}

Most of the respondents in this study had tumultuous personal histories characterised by split families, physical abuse or neglect, and frequent drug and alcohol use in the homes in which they grew up. The extent of the disarray was commonly reported in the interviews (box 2). Although dramatic, such reports were routine rather than exceptional among interviewees. Most of the respondents talked about their childhood experiences generally, but several drew connections between their past experience of abuse or neglect and their present inability to trust others: "I don't know, I just . . I've never trusted people, I've never trusted them at all. I think it stems from when I was younger and all that 'cos [sic] my upbringing wasn't the best of upbringings really" (respondent 7). This participant in particular was able to draw a link between his childhood experience and his sense of distrust.

\section{Distrust}

Within this context, how distrust emerged as a major theme in the analysis is understandable. To distrust is to regard as untrustworthy, to regard with suspicion, or to lack faith or confidence in something. It is the expectation that others will not act in one's best interest. ${ }^{15}$ Scholars understand that trust is built on the normality, predictability, and reliability of one's social environment. ${ }^{16}$ Thus, when the rules governing social interaction have been significantly eroded, as with participants in this sample, trust is likely to deteriorate. Several types of distrust characterised this sample. Many men expressed a general distrust of almost all people; some reserved trust only for the closest of family members. Others proclaimed a distrust for everyone, including relatives: "I don't have no trust in the system. I don't trust the system one bit, I hate the system. All they've ever done is shit on my life. Why should I trust them? Probation, they've shit on me, DTTO, they shit on me, course they shit on you, everybody shits on you. So I don't trust nothing or no- one. I don't trust my missus, I don't trust my own mum and if I don't trust my own mum I ain't going to trust no-one" (respondent 3).

The most common types of distrust were a generalised distrust towards "the system" and distrust directed specifically at healthcare professionals (box 3). The second type was often expressed as specific negative beliefs; for instance, a commonly reported belief was that healthcare professionals (most often doctors) "just don't care," "just want to medicate," or "treat patients superficially." Many respondents based these perceptions on negative experiences with healthcare professionals, whereas others discussed these feelings more generally, not referring to actual experiences. These categories were not mutually exclusive, as some respondents expressed a combination of these sentiments: "They don't care one bit, they really don't care. They must have a flippin' ... programme to follow or something, where they must have to tick boxes or something" (respondent 27).

\section{Box 2: Chaotic family background}

Respondent 3: "I don't talk to my dad." Interviewer: "Why?" R3: "He raped my sister for 6 years and beat the crap out of me and my brothers for 6 years. So now I don't talk to my dad. He beat the crap out of his missus even when we lived with him. My step mom when I was 3 or 4. She was a bitch, I hated her." I: "Really?" R3: "Yeah. When he wasn't beating us, it was her, but my mum, she never laid a finger on me in my life, she never would, she wouldn't dare. She's still messed up in her own little way. Well, mum introduced me to drugs."

I: "So why did you get fostered when you were 14?" R24:

"'Cos my mum went on a bender. (Laughs.) She went on a mad one. And I was sick of living in fields and in buses and stuff, so I ended up getting put into foster care."

R25: "But when I was in with my real dad I was just getting beaten around a lot. He had no particular reason to do it, I think it was just he was lonely and that and he had no other way to take it, apart from on us, so we got hit around. And then one day I left and went to my mum's and that was it."

R15: "I was in care from the age of 3, 'cos me mum's got really bad, chronic arthritis and she couldn't cope with all of us, we was little tearaways and she couldn't cope with us. My sisters were adopted, I was just put on a full care order. I was in children's homes, I was fostered for 6 years and I still keep in contact with the foster parents, they're pretty good. But since I left care basically that's all I've been doing is coming to prison."

R18: "Mother and father were divorced before I was born. Mother was only 16 when she had me, so really young. Dad was only young as well. My mother's dead, she was killed in a car accident a few year back. She was dead with drinking, though. I'm a heavy drinker myself, me father was a heavy drinker."

R27: "It was hard to catch up, yeah, and I just hated it. And coming home was even worse, living at home was worse, because my mum used to be ... my mum rules with her fists, do you know what I mean, she rules with her fists. And that was just crazy. She used to slap me about all the time and put a pillow over my head, trying to suffocate me." 


\section{Box 3: Distrust as a barrier to seeking help}

Respondent 4: "It wouldn't, because at the end of the day they'd think more drugs again, just give you drugs, and I'm anti-drugs, I do not like drugs, apart from what I need to keep me alive, like aspirin basically to thin me blood. No, I've seen it all my life, you know. I mean ... they've got a problem, they go to the doctor's-oh yeah, we'll give you this. Now a drug doesn't solve anything, it makes it worse. No, I wouldn't. Well, the doctors used to be caring people, that's why they went into the profession, to help us, to help people. But nowadays it's ... you're lucky if you ... they don't care. That's the problem with this country nowadays, nobody cares."

R20: "Er, well the GPs in England are not, um, very helpful in that way. They would rather just look at you and go: right well you can have that tablet. I've tried committing suicide in here a few times and they say we'll take you to healthcare for the night, you'll see the doctor-and the doctor says, oh, how are you feeling, you look all right to me, and he sends me back to the wing. They don't really understand what people are going through-they pretend that they do, but all they're doing is saying, oh, we don't want you over here, you can go back to the wing." Interviewer: "What's your experience of GPs been like?" R24: "Err ... rubbish really, they just try and pawn me off with drugs that don't actually help the situation. The government's answer is use medication to fuck the nation. (Laughs.) They either want to take blood from me or they want to give me drugs, which I'm not interested in."

I: "You don't think that talking about it would help?" R15: "No, not really, it's like... anyone can sit there and tell you that there's something wrong with you, but how many people do you know can actually sit there and tell you how you can get rid of it?"

A subset of men in this group were less angry but simply did not feel comfortable discussing personal problems with healthcare professionals because no previous relationship existed: "I don't know, it's just going to see a complete stranger. Yeah he's a doctor, but it's just going to speak to him, a complete stranger, and tell him all your problems. No, it's just not my type" (respondent 1). Other respondents lacked confidence that general practitioners or mental health professionals could do anything to help them when they had mental health problems. For instance, one respondent remarked that he would never see a general practitioner if he was having mental health problems: "Well, what are they going to do? Are they going to sort your problems? No chance. Are they going to give me medication? What are they going to do? There's nothing they can do, is there?" (respondent 18). Some based this lack of confidence on previous experiences in which they felt that they were not taken seriously, which often led to a sense of hopelessness among interviewees. Others simply did not believe that the system had anything constructive to offer to solve their complex problems. This form of distrust seemed to be based on logical conclusions about likely lack of efficacy in the face of insurmountable problems, rather than on an emotional response to past experiences.
Fear of diagnosis of mental illness

Another impediment to help seeking for many participants was the fear of a diagnosis of mental illness. Many participants feared that being formally diagnosed as having a mental health problem would result in them being stigmatised by friends, family, or others-that is, they feared the external or social consequences of the label: "Like I say, like, you know, it seems either if you're ill or just off your head . . no, not ill, sorry, if you're just off your head, say a criminal and going out there and doing crime and stuff and all your friends are there for you, and then you are diagnosed with a mental illness, then they all seem to turn their back like . . . I mean no-one . . . it seems people are scared of mental illness. That's one of their worst fears, actually being diagnosed as mentally ill you know" (respondent 8).

Others divulged that they were not personally ready to accept such a diagnosis, often stating that they did not want to know about, or were not ready to admit, the existence of a mental health problem because knowing would mean having to confront the problem. Although both fears are likely to be inter-related, one can be conceptualised as a fear of the external consequences of the diagnosis, whereas the other can be thought of as a fear of the internal costs of admission (box 4).

\section{Factors that promote help seeking}

In contrast with the participants discussed above, however, a few interviewees did report trust or confidence in the ability of their general practitioner to help them with mental health problems. Some respondents trusted their general practitioners because they had established a previous positive relationship with them, whereas others remarked that they had been treated with respect by a doctor or other healthcare professional in the past (box 5). For instance, participants spoke of the importance of characteristics that indicate respect, such as attentive listening or being dealt with in a compassionate manner. These categories are not mutually exclusive. Several of the respondents who expressed a readiness to consult had been treated with respect by a healthcare professional at some point in their lives, and this had enabled them to establish a positive relationship with their general practitioner.

\section{DISCUSSION}

In this study we used a qualitative approach to explain the dynamics that influenced help seeking behaviour among male offenders before entering and after leaving prison. All of the identified themes-a chaotic upbringing, a fear of diagnosis, and distrust of the system-seemed to influence the help seeking behaviour of this sample of incarcerated men. Difficult childhoodscharacterised by violence, neglect, and abandonmentprovide a fertile breeding ground for distrust of close relatives, "the system," and health professionals. For all but a few participants, the accompanying fear of stigma or of "self knowledge" resulted in a virtual absence of engagement with community based mental health services. 
Box 4: Fear of diagnosis as a barrier to help seeking

Respondent 33: "'Cos it's a hard thing to admit, isn't it? It's like saying you're weak basically. Interviewer: "You think so?" R33: "Yeah." I: "So you think it would be saying you're weak if you admitted it?" R33: "Yeah, saying that you can't handle everyday life really, so you're classed... to me, I would class myself as weak if I'd got to go and say I've got a problem. And if I don't admit it, I haven't got it. So that's the other way of looking at it, isn't it?" R28: "Well, you're obviously a bit wrong if you've got a mental health problem, that's how some people see itnot myself personally, but you know yourself how some people see it. And to actually spill your guts and talk about your personal stuff to someone is another big barrier, isn't it? Nowhere in life are you encouraged to do that ever, so you've really got to take it on board for yourself-'well, actually l'm going to have to speak about all this stuff to get better.' That's a big barrier, I think." R8: "Yeah. As I say, I have got some good friends out there. But they are normal people, but they wouldn't know how to understand someone getting ill, like, you know. They just think: he's going off his head, like, you know? Just leave him to it, which I think a lot of the time I shouldn't be like that, you know. Even though you've got to be quite bad for that ... for that to happen. But thinking in the past, I was actually quite bad, like, you know." I: "Yeah. Right. So you're afraid you may be ..." R8: "Afraid of the stigma of, you know, being... well you are mentally ill, like you know, deal with that, do you know what I mean?" I: "Yeah." R8: "It would be quite hard for me to deal with, where l'd rather... well you had an episode you are normal, carry on with your life, like, you know." I: "Right." R8: "I'd rather that than, you know, well, not be ignorant to it but be a little bit ignorant to it ... definitely." R15: "I suppose it's because half the time people will tell you the truth, like if there's something wrong and they're telling you it's wrong, it's the truth (laughs), it's hard to handle sometimes. I don't know. I just don't like sitting there, being told this is wrong with you, that's all. I know what's wrong with me."

The $100 \%$ agreement to participate and the fact that a substantial number of participants were re-interviewed after release are strengths of the study and suggest that the findings are important to people who plan and provide health care for offenders in the community. The ethics committee that approved the study did not feel that the small food voucher payment made to participants was excessive inducement to participation; furthermore, the surprise expressed by participants after this token gesture suggested that it had not acted as a major factor influencing their involvement. The generalisability of our findings is limited because the sample was drawn from a prison in southwest England that predominantly holds white British offenders with sentences of less than one year; to what extent our findings might relate to long term offenders, those from black and ethnic minorities, or women is therefore unclear. The perspectives explored here, however, are illustrative of people commonly referred to as the "revolvers" or "churners," as they are frequently in and out of the prison system. Some people maintain that this group is at higher risk for suicide and self harm

\section{Box 5: Factors that promote help seeking}

Respondent 15: "I have a good chat with ... I've got a good relationship with my doctor, really good, he understands and that. Interviewer: "So you would consult a GP if you were feeling depressed?" R15: "Yeah, definitely. My GP's quite good, he's not one to sit there and not listen, he'll listen to you, whereas counsellors they're more like 'I think this is wrong' and 'why don't you talk about this'... but the GP is different."

I: "So you feel like you could trust the doctor? R9: "Family doctor yeah." I: "Why a family doctor?" R9: "Well ... he obviously knows things like... knows our background, and they know what else we've gone through and all that."

R28: "Yeah we built up a good rapport, yeah, so she knew a lot about me. And I knew stuff about her as well ... not so much her personal life, but just like little things about what she was going to do that day or something, so the next time I saw her l'd go, oh, did you go do such and such, and it was the basis for a conversation. She was just brilliant. Yeah I don't know where I'd be now without her." R21: "I'd just go to the doctor like, he's fairly friendly, Mr N, he's great he is. I just go and see him like. And he's got time for everyone he has."

I: "Who would you contact if you were experiencing mental distress?" R20: "Err ... my doctor, my family doctor, he knows I've been in prison and he knows I've been arrested, but he still treats me as a normal person, he doesn't try and talk down to you and he doesn't say, oh, you're alright, you go and do what you want to do. He tries to resolve the problem."

than long term prisoners, because when released they do not fall under probation services and therefore do not benefit from any type of post-release sentence planning. ${ }^{17}$ This study begins to shed some light on the experiences of a highly vulnerable group of offenders who have limited post-release support.

\section{Emerging themes}

Overall, lack of trust emerged as the most prominent theme in prisoners' talk about their likelihood of seeking help from health professionals. Trust has traditionally been considered the "cornerstone" of the doctorpatient relationship. ${ }^{18}$ Without it patients may be unlikely to disclose medically relevant information, let alone deeply personal and potentially stigmatising information about their mental health problems. This may be particularly true for people who have led lives characterised by chaos, abuse, and institutionalisation, such as those in this sample. Many of the respondents in this study did not feel that health professionals genuinely cared about them or had the ability to help with mental health problems. It is tempting to speculate that these findings may relate to the challenging and sometimes anomalous roles and attitudes that health professionals show during the course of consultations, ${ }^{19}$ which form the basis of the "clinical gaze." ${ }^{20}$ Other participants were hesitant to seek help because they feared a formal diagnosis of mental illness. Some of these men feared the stigma that such a diagnosis would bring, whereas others feared that a diagnosis would mean having to confront the problem. 


\section{WHAT IS ALREADY KNOWN ON THIS TOPIC}

Men who are, or have been, incarcerated have higher rates of mental illness and suicide risk than the general population and lower rates of use of mental health services

Limited information is available on the perceptions and beliefs that influence help seeking among this group

\section{WHAT THIS STUDY ADDS}

Barriers to help seeking among prisoners include a chaotic family history, distrust of "the system," and a fear of the social and individual consequences of a diagnosis of mental illness

These factors can make people distrustful of doctors and deter them from seeking medical help

General practitioners and other healthcare professionals have a role in facilitating help seeking by treating people with a criminal record in an attentive and respectful manner

Prior et al and others have reported that stigma was not in itself a barrier to disclosure of emotional problems, but that people suppressed information during general practice consultations because they doubted whether medicine had anything to offer. ${ }^{2122}$ Our findings suggest that offenders in particular are sceptical about the ability of doctors to offer anything other than palliative approaches for mental distress.

That many people consult their general practitioner because a close friend or relative is concerned and has encouraged them to do so is well known. ${ }^{2324}$ Absence of stable, supportive relationships and the consequent lack of potential for lay referral may further explain these offenders' disinclination to consult. At the same time, it underlines the potential value of consulting for these troubled and needy men, for whom an enduring relationship with a sympathetic general practitioner may serve as a lifeline. ${ }^{25}$

For the few respondents who reported that they would turn to a general practitioner or other healthcare professional for mental distress, trust seemed to have an important role, and this was based on previous positive experiences of health care. A recent study of suicidal men by Strike et al has drawn attention to the fact that negative experiences often lead to avoidance of healthcare settings and that this can result in crisis and involuntary contact with services. ${ }^{26}$

\section{Recommendations for care}

Given this information, how can healthcare professionals help to foster help seeking and trust among this population? We can make several tentative recommendations for care within and outside prisons on the basis of these findings. More information specifically designed for prisoners and distributed within the prison may help to de-stigmatise mental illness among this group. Pre-release preparation might include group discussions about recognition of mental health problems, responses to distress, and the potential value of accessing health services. For offenders with an identified history of mental illness, individualised crisis plans and links with community based services could be developed.

Like most people, the participants in this study wanted to feel listened to, acknowledged, and treated as individuals by their general practitioners. Although trust is often established through continuity of care in the course of the patient-clinician relationship, ${ }^{27}$ trust can also be established by seemingly trivial gestures that indicate respect. By ensuring that a positive precedent is set, particularly for sceptical groups such as exprisoners, general practitioners may be able to encourage future help seeking. Finally, as most health professionals are not trained to manage people who have been involved in the criminal justice system, ${ }^{28}$ we recommend appropriate staff training and development.

We thank the National Institute of Mental Health in England for funding the research on which this paper is based, and all the interviewees who agreed to take part and share their experiences. We also thank Chandra Fowler, the Revolving Doors Agency, and the Revolvers; the governors and personnel of the prison for letting us conduct the research; Donna Skinner for her ongoing support throughout the research; Michele Dillon, Chris Colocousis, and Joy Choules for commenting on earlier drafts; and members of the project advisory panel.

Contributors: JC was principal investigator, sought funding for the study, and contributed to designing and planning the study and writing the paper. $\mathrm{AH}$ designed the study, did the interviews, led the analysis, and was lead autho for the paper. RB was a co-investigator; sought funding; designed the study; and participated in the planning, analysis, and writing of the paper. $\mathrm{DH}, \mathrm{CO}$, and $\mathrm{PA}$ contributed to design and planning the research and writing the paper; $\mathrm{DH}$ also contributed to the analysis. JC is the guarantor.

Funding: National Institute of Mental Health in England.

Competing interests: None declared.

Ethical approval: South Essex local research ethics committee, reference number 05/Q0302/110.

1 Biddle L, Gunnell D, Sharp D, Donovan JL. Factors influencing help seeking in mentally distressed young adults: a crosssectional survey. Br J Gen Pract 2004;54:248-53.

2 Sattar G. The death of offenders in England and Wales. Crisis 2003;24:17-23.

3 Lloyd M. Suicide and self injury in prison: a literature review. London: HMSO, 1990. (Home Office Research Study No 115.)

4 Pratt D, Piper M, Appleby L, Webb R, Shaw J. Suicide in recently released prisoners: a population-based cohort study. Lancet 2006;368:119-23.

5 Deane FP, Skogstad P, Williams MW. Impact of attitudes, ethnicity, and quality of prior therapy on New Zealand male prisoners' intentions to seek professional psychological help. Int J Adv Couns 1999;21:55-67.

6 Akhurst M, Brown I, Wessely S, West Yorkshire Probation and After-care Service, West Yorkshire HA, Association of Chief Officers of Probation. Dying for help: offenders at risk of suicide. Leeds: Association of Chief Officers of Probation, 1994.

7 Oliver MI, Pearson N, Coe N, Gunnell D. Help-seeking behaviou in men and women with common mental health problems: cross sectional study. Br J Psychiatry 2005;186:297-301.

8 Donovan JL, Blake DR. Qualitative study of interpretation of reassurance among patients attending rheumatology clinics: "just a touch of arthritis, doctor?" BMJ 2000;320:541-4.

9 McCabe R, Heath C, Burns T, Priebe S. Engagement of patients with psychosis in the consultation: conversation analytic study. BMJ 2002;325:1148-51.

10 Britten N, Stevenson FA, Barry CA, Barber N, Bradley CP. Misunderstandings in prescribing decisions in general practice: qualitative study. BMJ 2000;320:484-8.

11 Pritchard C, Cox M, Dawson A. Suicide and 'violent' death in a six-year cohort of male probationers compared with pattern of mortality in the general population: evidence of accumulative socio-psychiatric vulnerability. J R Soc Health 1997;117:180-5.

12 Mays N, Pope C. Qualitative research in health care: assessing quality in qualitative research. BM/ 2000;320:50-2.

13 Ziebland S, McPherson A. Making sense of qualitative data analysis: an introduction with illustrations from DIPEx (personal experiences of health and illness). Med Educ 2006;40:405-14.

14 Morse J. 'Perfectly healthy but dead': the myth of inter-rater reliability. Qual Health Res 1997;7:445-7.

15 Govier T. Is it a jungle out there? Trust, distrust, and social reality. Dialogue 1994:33:237-52.

16 Goffman E. Relations in public: microstudies of the public order. New York: Basic Books, 1971 
17 Her Majesty's Chief Inspector of Prisons for England and Wales, HM Inspectorate of Probation, Home Office. Through the prison gate: a summary of HM Inspectorates of Prisons and Probation joint thematic report. London: Home Office, 2001.

18 Rowe R, Calnan M. Trust relations in health care-the new agenda. Eur I Public Health 2006;16:4-6.

19 Ben-David JJ. The professional role of the physician in bureaucratized medicine: a study in role conflict. Hum Relat 1958;11:255-74.

20 Armstrong D. Political anatomy of the body: medical knowledge in Britain in the 20th century. Cambridge: Cambridge University Press, 1983.

21 Prior L, Wood F, Lewis G, Pill R. Stigma revisited, disclosure of emotional problems in primary care consultations in Wales. Soc Sci Med 2003;56:2191-200.
22 Pill R, Prior L, Wood F. Lay attitudes to professional consultations for common mental disorder: a sociological perspective. $\mathrm{Br}$ Med Bull 2001;57:207-19.

23 Zola IK. Pathways to the doctor-from person to patient. Soc Sci Med 1973;7:677-89.

24 Freidson E. Profession of medicine: a study of the sociology of applied knowledge. New York, London: Harper and Row, 1970.

25 Mechanic D. The concept of illness behavior. J Chronic Dis 1962;15:189-94.

26 Strike C, Rhodes AE, Bergmans Y, Links P. Fragmented pathways to care: the experiences of suicidal men. Crisis 2006;27:31-8

27 Stewart M. Continuity, care, and commitment: the course of patient-clinician relationships. Ann Fam Med 2004;2:388-90.

28 Viggiani N, Orme J, Powell J, Salmon D. New arrangements for prison health care. $B M J$ 2005;330:918.

Accepted: 28 November 2006 